\title{
A Case of Phlegmasia Cerulea Dolens
}

\author{
Somasamudra $\mathrm{P}^{*}$ \\ Broomfield Hospital, Chelmsford, United Kingdom
}

${ }^{*}$ Corresponding author: Somasamudra P, Broomfield Hospital, Chelmsford, United Kingdom, E-mail: pramodsbly@yahoo.com

Citation: Somasamudra P (2017) A Case of Phlegmasia Cerulea Dolens. SAJ Case Rep 4: 405

Article history: Received: 28 November 2017, Accepted: 28 November 2017, Published: 30 November 2017

\section{Description}

A $50 \mathrm{yr}$ old gentleman with a diagnosis of metastatic pancreatic cancer was admitted with a history of swollen leg. He had widespread metastatic disease and he had a poor performance status. He was not suitable for chemotherapy or aggressive treatment in view of his poor performance status and extensive metastatic disease with very poor prognosis. He was not able to mobilise and he was bed bound. He was for palliative management with symptom control.

His leg was swollen and it was cyanosed with purplish/bluish discolouration. He had an US Doppler which suggested extensive DVT of the deep venous system. He was started on anticoagulation (Figure 1,2 and 3).

He was referred to a tertiary centre for further management but as his prognosis was extremely poor with poor performance status he was manged with anticoagulation.

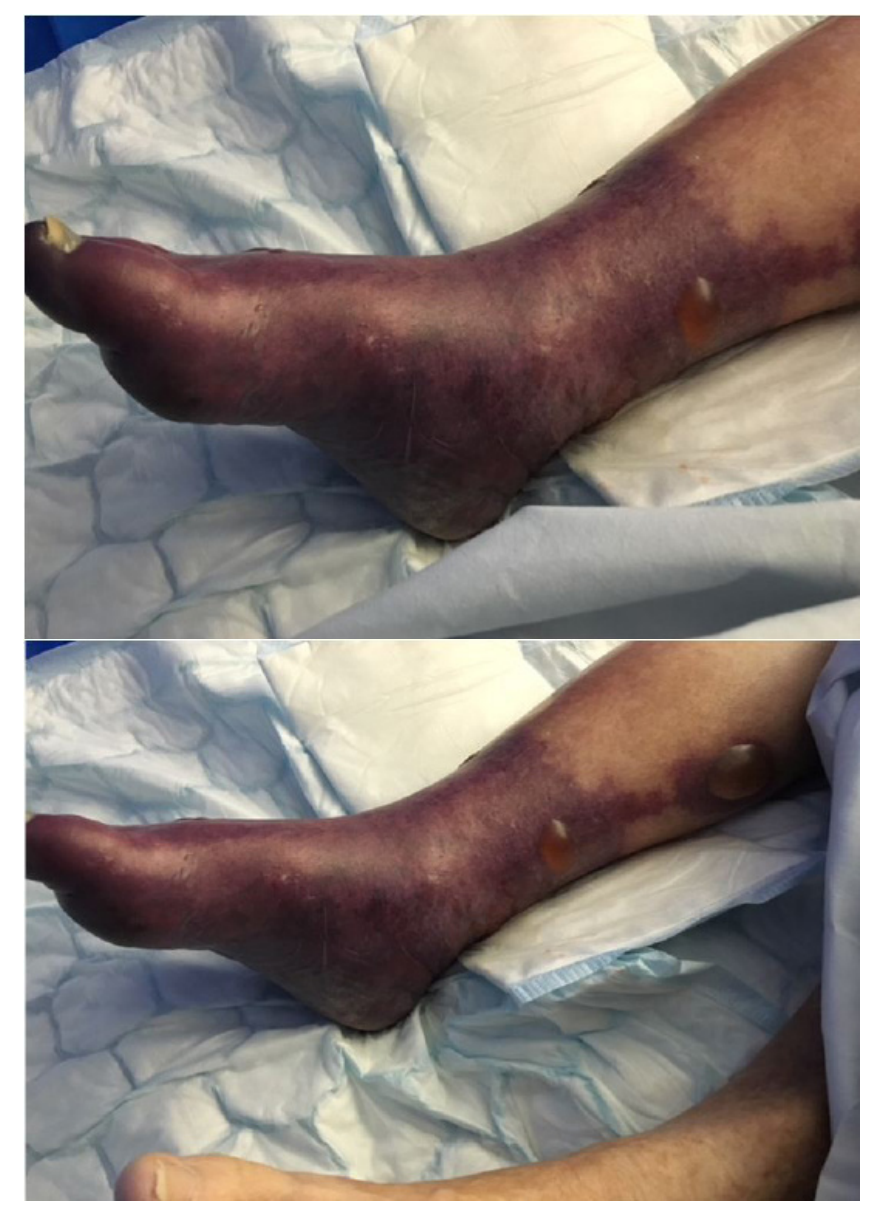




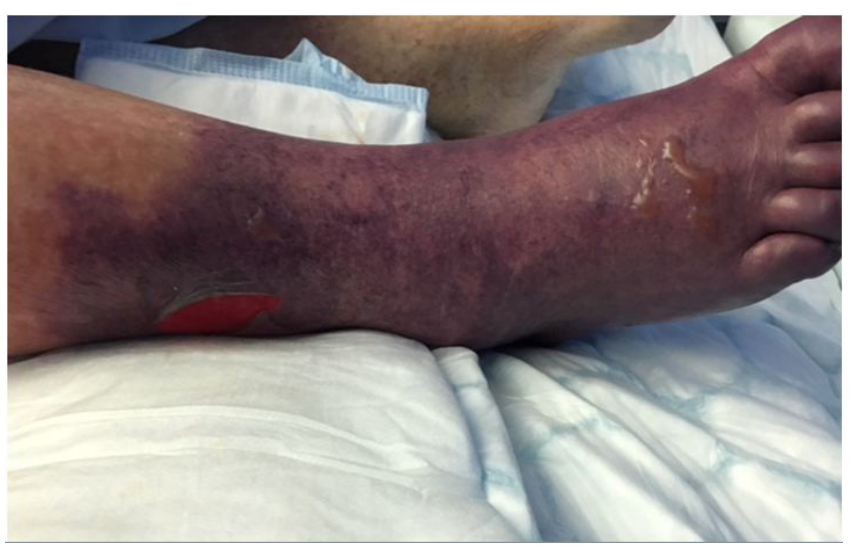

Phlegmasia stems from the greek term phlegma meaning inflammation. It is characterised by severe swelling and cyanosis and discoluration of the extremity. There is capillary involvement in $40-60 \%$ of cases. In phlegmasia alba dolens the venous drainage is decreased but still present, the lack of cyanosis differentiates this from phlegmasia cerulea dolens.

Carotid, coronary and iliac artery stenosis are known to occur around 10 yrs after radiotherapy to head, neck, breast and pelvis. Radiation induces endothelial damage followed by proliferation of smooth muscle cells resulting in luminal stenosis and thromboisis

\section{Risk Factors}

- Malignancy

- Femoral vein catheterisation

- Heparin induced thrombocytopenia

- Antiphospholipid syndrome

- Surgery

- CCF

- Pregnancy

- Radiation induced venous stenosis

\section{Clinical Features}

- Leg swelling

- Colour change

- Venous congestion

- Venous gangrene

- Shock

- Venous gangrene

- Shock

\section{Treatment}

Options of treatment include anticoagulation, thrombectomy and thrombolysis.

In patients with massive ileofemoral DVT and symptoms less than 14 days, with good functional status, catheter directed thrombolytic therapy and or clot removal via catheter or surgical route can be tried. The complications of thrombolysis are haemorrhage and reperfusion injury.

In phlegmasia cerulea dolens the primary lesion is the thrombosis within the capillary bed leading to compartment syndrome and subsequent gangrene. It is therefore logical to deliver the lytic agent to the capillary bed by the arterial route.

The advantages of thrombolysis via commom femoral artery are low dose and lytic agent is delivered to the capillary bed.

\section{Complications}

Venous infarction, gangrene, pulmonary embolism, hypotension, shock and arterial insufficiency.

\section{Learning Points}

- To be aware of Plegmasia cerulea dolens in a case of discolured swollen leg

- Earlier diagnosis and good functional status is essential for optimal treatment

- To differentiate it from phlegmasia alba dolens 


\section{References}

1. T. Ikegami A, Kuriyama S, Matsukubo (2016) Clinical picture of phlegmasia cerulea dolens -An Int J Med 281-2.

2. Halle M, Gabrielsen A, Paulsson-Berne G, Gahm C, Agardh HE, et al. (2010) Sustained Inflammation due to nuclear factor Kappa B activation in irradiated human arteries. J AM Coll Cardiol 55: 1227-36.

3. Lessne ML, Bajwa J, Hong K (2012) Fatal reperfusion injury after thrombolysis for Phlegmasia cerulea dolens. J Vasc Interv Radiol 23: 681-6.

4. Uptodate.com 